\title{
Invitation to the 4th Asia-Pacific Congress of the Asia-Pacific Military Medicine (PAPCMM)
}

\author{
Farshad Najafipour ${ }^{1, *}$ \\ ${ }^{1}$ Brigadier General, MD, PhD, Sports Physician and Sports Psychologist, ICMM Delegate, MOD, IR Iran \\ "Corresponding author: Farshad Najafipour, Brigadier General, MD, PhD, Sports Physician and Sports Psychologist, ICMM Delegate, MOD, IR Iran. E-mail: \\ drnajafipour2002@yahoo.com
}

Received 2017 June 02; Accepted 2017 June 08.

\section{Dear Editor,}

The 4th Asia-pacific congress of the asia-pacific working group of international committee of military medicine (ICMM), (PAPCMM) is held in Tehran, Iran in the spring or summer of 2017. The congress is hosted by the Armed Forces Medical Services, IR. Iran, in accordance with the statutes of the secretariat general of the ICMM.

The main theme of the congress is "Military Medicine Updates: Looking Forward". The broad subjects under the main theme are terrain specific military medical support: challenges and solutions, health protection and promotion in the military environment: experiences and best practices, combat medical support: technological advances and implications, NBCRe, post-traumatic stress disorder (PTSD), and humanitarian aid and disaster relief.

The congress has simultaneous scientific sessions, poster presentations, round tables, panel discussions, and workshops encompassing the broad themes. Eminent experts in the field of military medicine deliver the keynote address and plenary talks.

Tehran is a blend of multiple cultures and is a symbol of Iran rich past and thriving present, where the history and the modernity converge seamlessly. It touches your mind and also your heart. The city offers the best of a rich history and a young evolving nation to its visitors, bringing people closer and inspiring their thoughts.

This meeting can be a perfect opportunity for all nations to learn about the best practices of military medicine, exchange information, and make friends. It is time to celebrate this event in this global city.

Brigadier General; Farshad Najafipour, MD, PhD

Sports Physician \& Sports Psychologist

ICMM Delegate, MOD, IR Iran

Secretariat of the Steering Committee

4th Asia-pacific congress of the asia-pacific working group of international committee of military medicine (ICMM), (PAPCMM) 